\section{Analysis of Effort for Plant Maintenance in Relation to Garden Composition}

\author{
Dennis P. Stimart ${ }^{1}$ and \\ William J. Martin ${ }^{2}$
}

AdDitionAl INDEX wORDs. labor, landscape, ornamental plants

Summary. The time required to maintain plants on a standardized basis (effort) was investigated in $\mathbf{2 4}$ gardens of various plant composition over 5 years. Cluster analysis of data grouped gardens into five clusters based on magnitude and timing of effort. Plants grown in containers required up to 20 times more effort annually than plants grown in other gardens in ground beds. Gardens planted with annuals required about $80 \%$ less effort than container gardens but $75 \%$ more effort than other gardens evaluated. As the number of taxa in gardens decreased, effort decreased and was less variable throughout the year. Enumeration of effort in relation to garden composition should be used to project management cost for gardens.

$\mathrm{D}$ esign and construction costs for gardens are calculable and used to plan and budget resources for the creation of gardens. This stage of a garden has definable costs. Commonly, knowledge regarding costs for gardens ends with construction, leaving the cost of maintenance unknown and only realized later by the recipient.

Garden maintenance is essential and influenced by garden composition, yet information on specific gardens is scant and poorly documented. At best, reference is made to gardens being high maintenance (Behme, 1969)

Department of Horticulture, University of WisconsinMadison, 1575 Linden Drive, Madison, WI 53706.

A note of gratitude to John Mather and William Hoyt, University of Wisconsin-Madison, for their assistance with data management. Use of trade names does not imply endorsement of the products named or criticism of similar ones not named.

${ }^{1}$ Professor and chair of department; to whom re print requests should be addressed. E-mail address: dstimart@wisc.edu

${ }^{2}$ Research associate. or low maintenance (Oehme and van Sweden, 1998; Ottersen, 1987) without further enumeration. Additionally, landscape maintenance sources (Angley et al., 2002; Colton, 1981; Dietrich, 1994; Fee, 2002) estimate labor need as frequency per year service is recommended for lawn, shrub and tree,flower beds, paved areas, etc. (Angley et al., 2002), or tasks associated with specific plant culture (DiSabato-Aust, 1998). The sources disregard garden composition and the number of service hours required to complete tasks. This approach assumes gardens of various compositions of assorted plant types require like amounts of labor.

Maintenance in private or public gardens is linked directly to success of gardens being so costly that it affects all aspects of garden management. In public gardens, maintenance reflects on achievement of fundraising, developing budgets, scheduling employment, organization, preservation of capital investment, quality programming, image, and posturing for change (Ode, 1987). Although importance of plant maintenance is recognized, little attention has focused on documenting and developing working data to manage labor allocation in relation to garden composition. Superficial documentation of labor weakens sound garden management strategies. This research investigated expenditure of physical energy for plant maintenance of 24 gardens of various structures over a 5 -year period for use in planning and managing gardens.

\section{Materials and methods}

This research was done at the Allen Centennial Gardens (ACG), Department of Horticulture, University of Wisconsin, Madison. The primary mission of the gardens is to provide an outdoor instructional and laboratory facility to university students enrolled in course work related to departments on campus, including: art, botany, entomology, horticulture, landscape architecture, plant pathology, and soils as well as related areas of interest. The gardens strive to inform and demonstrate use of traditional and novel plants in diverse landscape settings. To accomplish this, the gardens constantly evolve to reflect the most recent innovations in horticulture and landscaping. A secondary function of the gardens is to provide an extension and outreach facility to the community.
Clientele includes university and college students, kindergarten through 12th grade students, garden clubs, master gardeners, the landscape and horticultural industries, and other groups and individuals with an interest in landscaping and horticulture. Finally, the gardens provide a pleasant horticultural setting for retreat and enjoyment.

Allen Centennial Gardens contain 24 gardens of various compositions (Table 1) on about 2.1 acres $(0.85$ ha). The type and number of taxa grown in each garden vary (Table 2 ). Additionally, about 117 containers are placed throughout the gardens featuring ornamentals, fruit, herbs, and vegetables grown in soil-based media. Tables, chairs, and benches are located

Table 1. Area of components in Allen Centennial Gardens, Department of Horticulture, University of Wisconsin, Madison.

\begin{tabular}{|c|c|c|}
\hline \multirow[b]{2}{*}{ Location } & \multicolumn{2}{|c|}{ Area } \\
\hline & $\mathrm{ft}^{2}$ & $\mathbf{m}^{2}$ \\
\hline \multicolumn{3}{|l|}{ Gardens } \\
\hline Containers ${ }^{\mathrm{z}}$ & 201 & 18.7 \\
\hline Small fruit & 332 & 30.8 \\
\hline Daylily & 344 & 32.0 \\
\hline Corner & 473 & 43.9 \\
\hline Sunny annual & 593 & 55.1 \\
\hline Herb & 648 & 60.2 \\
\hline Tapestry des fleur & 840 & 78.0 \\
\hline Understory & 908 & 84.4 \\
\hline Vegetable & 1,106 & 102.8 \\
\hline Italian & 1,240 & 115.2 \\
\hline French & 1,277 & 118.6 \\
\hline Iris & 1,421 & 132.0 \\
\hline Orchard & 1,456 & 135.3 \\
\hline Shrub & 1,494 & 138.8 \\
\hline English & 1,500 & 139.4 \\
\hline Rain & 2,206 & 204.9 \\
\hline Water & 2,300 & 213.7 \\
\hline Victorian & 2,659 & 247.0 \\
\hline Dwarf conifer & 2,813 & 261.3 \\
\hline Turf & 3,217 & 298.9 \\
\hline Hillside & 5,151 & 478.5 \\
\hline New American & 5,413 & 502.9 \\
\hline Rock & 7,868 & 731.0 \\
\hline Woodland & 8,060 & 748.8 \\
\hline Total & 53,520 & $4,972.2$ \\
\hline Buildings $^{y}$ & 3,472 & 322.6 \\
\hline Driveways & 3,746 & 348.0 \\
\hline Walkways & 15,966 & $1,483.3$ \\
\hline Miscellaneous $^{x}$ & 14,772 & $1,372.4$ \\
\hline Grand Total & 91,476 & $8,498.4$ \\
\hline
\end{tabular}

${ }^{\mathrm{z}} 117$ containers of various shapes and sizes. yavilion in English garden, gazebo in hillside garden, and service building.

${ }^{x}$ Additional areas not included in study. 
Table 2. Description and average number of taxa per garden at Allen Centennial Gardens, Univ. of Wisconsin, Madison.

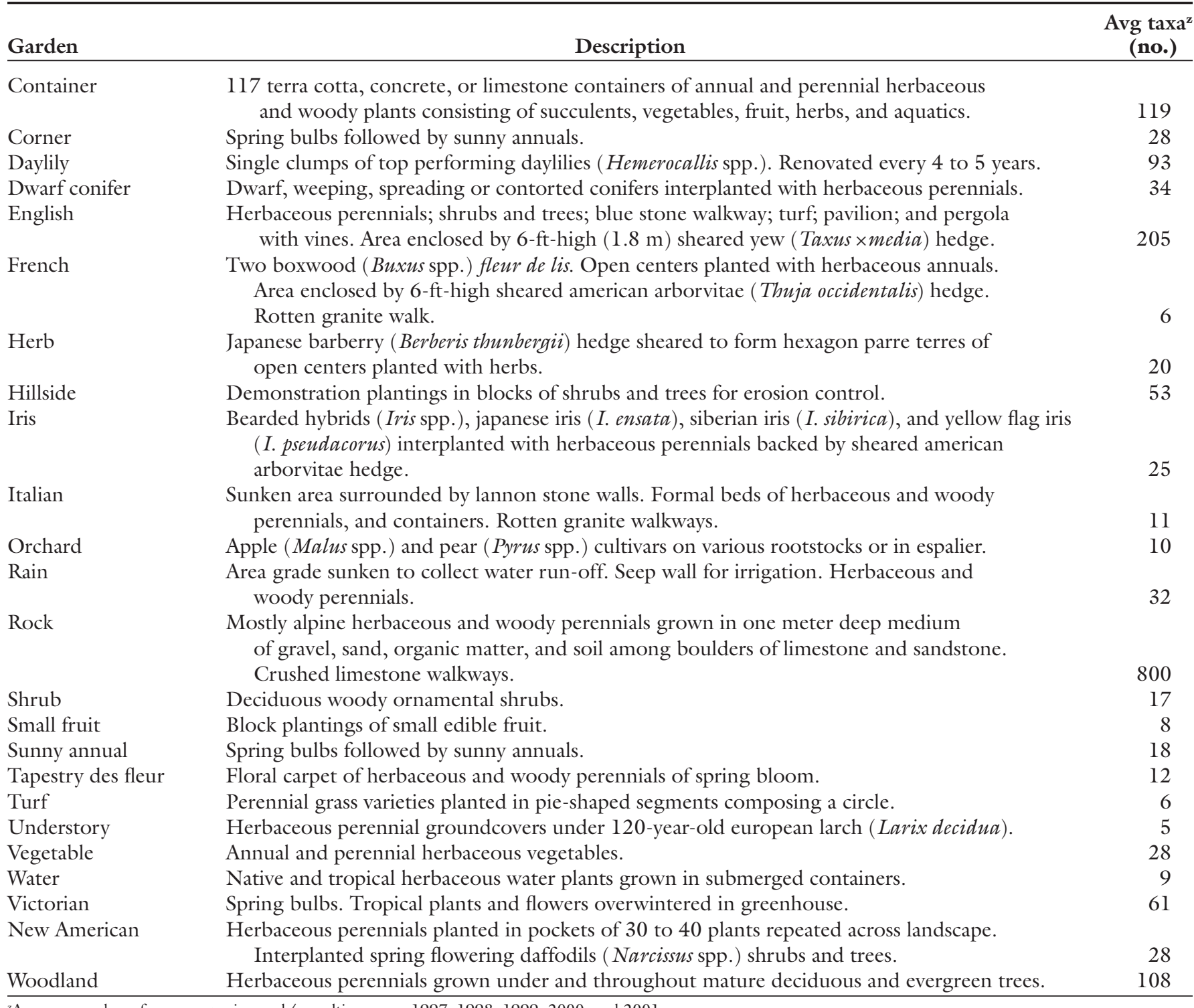

${ }^{2}$ Average number of genera, species, and/or cultivars over 1997, 1998, 1999, 2000, and 2001.

throughout the gardens to accommodate users, and provide privacy and viewing sites. Financial support comes from private donations raised through the University of Wisconsin Foundation. The gardens are open daily during daylight hours free of charge.

Allen Centennial Gardens surround a Victorian Gothic residence on the National Registry of Historic Buildings formerly used as a residence by the deans of the College of Agricultural and Life Sciences. The ACG are located at lat. $43^{\circ} 08^{\prime} \mathrm{N}$, long. $89^{\circ} 20^{\prime} \mathrm{W}$, at 844.5 $\mathrm{ft}(257.40 \mathrm{~m})$ elevation. Buettner and Associates, Fox Point, Wis., designed the ACG, and construction was initiated in 1986 and completed in 1993. Median date of last frost in spring is 12 May, with it occurring on or after 30 Apr. in $10 \%$ of the years. Median date of first frost in the fall is 28 Sept., with it occurring on or before 19 Sept in $10 \%$ of the years. Median growing season is $140 \mathrm{~d}$ with a range of 116 to $154 \mathrm{~d}$. Photoperiod on 21 June is $15 \mathrm{~h} 23 \mathrm{~min}$. Annual precipitation is 30.9 inches $(78.49 \mathrm{~cm})$ of rain and 43.2 inches $(109.73 \mathrm{~cm})$ of snow. From April through October, average high temperature is $71.0{ }^{\circ} \mathrm{F}(21.67$ ${ }^{\circ} \mathrm{C}$ ) with the average low during this period in April at $56.7^{\circ} \mathrm{F}\left(13.72{ }^{\circ} \mathrm{C}\right)$ and the average high in July at 82.4 ${ }^{\circ} \mathrm{F}\left(28.00{ }^{\circ} \mathrm{C}\right)$. From April through October, average low temperature is $47.8^{\circ} \mathrm{F}\left(8.78^{\circ} \mathrm{C}\right)$ with the average low during this period in April at $34.1^{\circ} \mathrm{F}$ $\left(1.17^{\circ} \mathrm{C}\right)$ and the average high in July at $59.5^{\circ} \mathrm{F}\left(15.28{ }^{\circ} \mathrm{C}\right)$.

Plant maintenance at the ACG is done by paid workers and volunteers, with the makeup of workers changing annually. Paid workers include one full-time head gardener and seven students, with one working full-time and six working half-time $(20 \mathrm{~h} /$ week $)$. The number of paid employees is based on available budget and 15 years experience of achieving the level of maintenance expected. Volunteers include Master Gardeners, garden club members, and general public. Previous work experience with landscape plants is required for paid employment but not for volunteers. Plant maintenance includes: mowing; trimming; edging; preparing beds; planting; fertilizing; mulching; irrigating; cultivating; transplanting; staking; dead-heading; management of weeds, insects, and disease; and winter protection.

Data were recorded each day over 


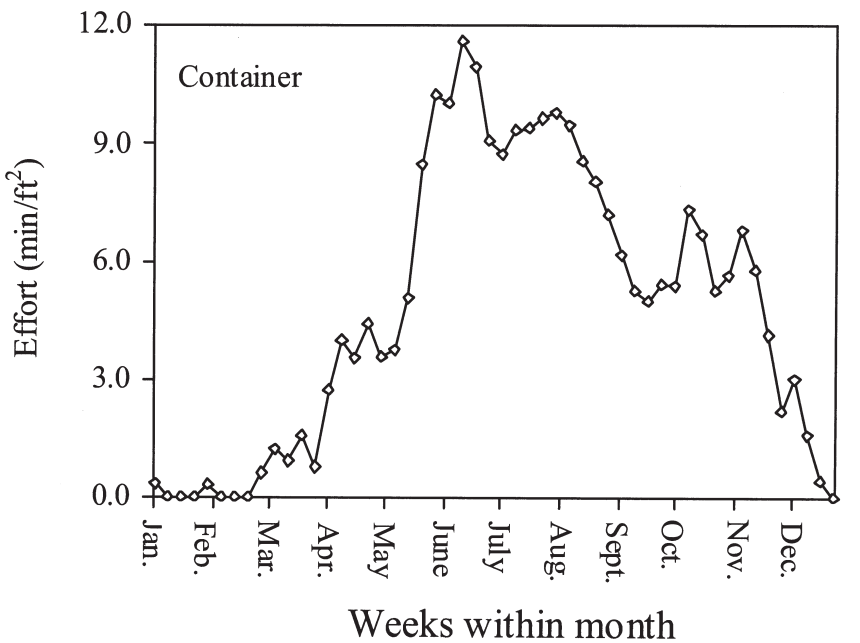

Fig. 1. Average weekly effort at Allen Centennial Gardens, University of Wisconsin, Madison, for plant maintenance by month over 5 years for gardens grouped into Cluster 1 by cluster analysis. Cluster 1 consists of 117 container gardens. $1 \mathrm{~min} / \mathrm{ft}^{2}=10.8 \mathrm{~min} \cdot \mathrm{m}^{-2}$.
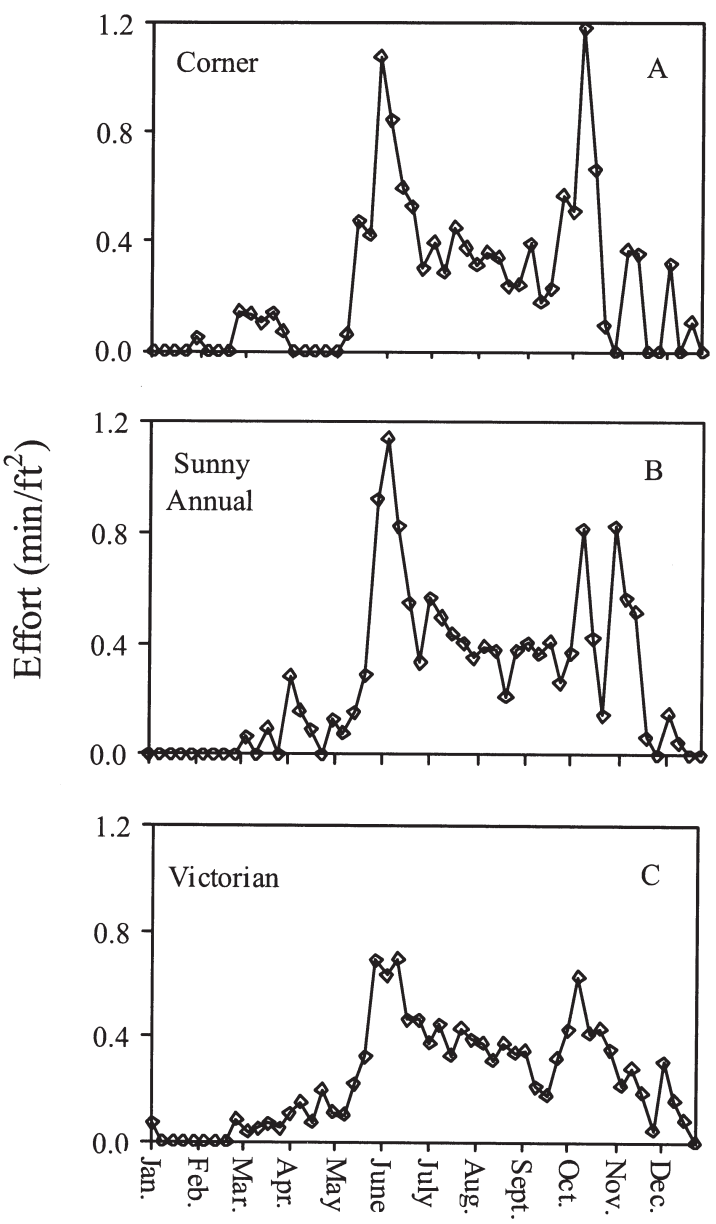

Weeks within month

Fig. 2. Average weekly effort at Allen Centennial Gardens, University of Wisconsin, Madison, for plant maintenance by month over 5 years for gardens grouped into Cluster 2 by cluster analysis. Gardens of Cluster 2 include: corner (A), sunny annual (B), and Victorian (C). $1 \mathrm{~min} / \mathrm{ft}^{2}=10.8 \mathrm{~min} \cdot \mathrm{m}^{-2}$.

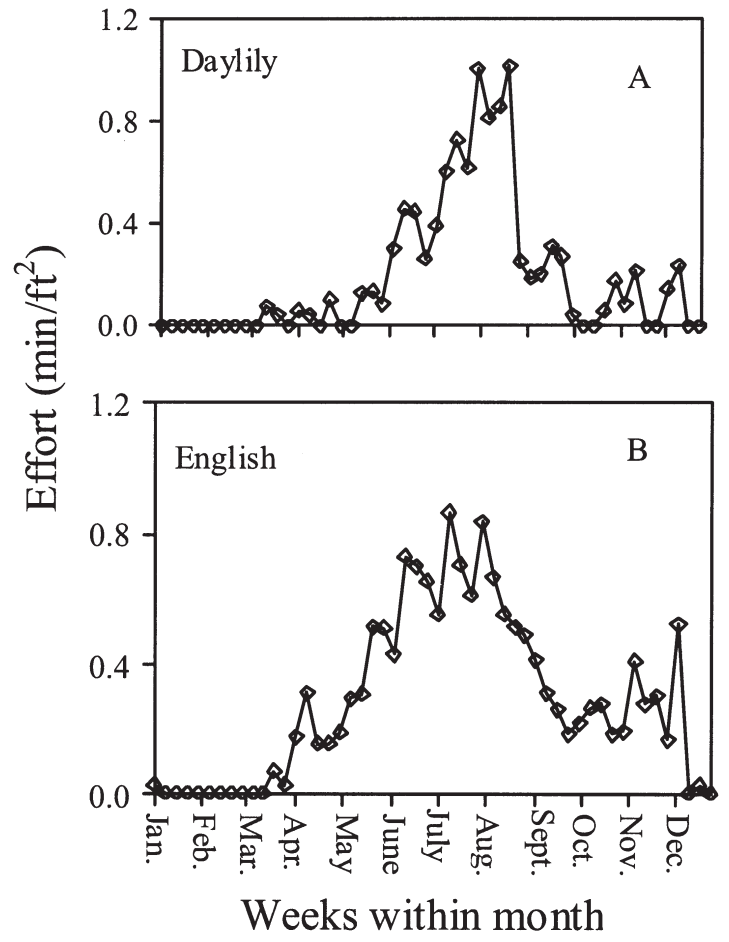

Fig. 3. Average weekly effort at Allen Centennial Gardens, University of Wisconsin, Madison, for plant maintenance by month over 5 -years for gardens grouped into Cluster 3 by cluster analysis. Gardens of Cluster 3 include: daylily (A) and English (B). $1 \mathrm{~min} / \mathrm{ft}^{2}=10.8 \mathrm{~min} \cdot \mathrm{m}^{-2}$.

5 years from 1997, 1998, 1999, 2000, and 2001 to the nearest 10 -min increment spent in each of 24 gardens. The area requiring plant maintenance was calculated for each garden evaluated (Table 1). Since planted square footage was different for each garden, plant maintenance per garden was standardized to minutes/square feet to allow for comparisons among gardens on an equal basis, henceforth referred to as effort. Total effort per garden per week was summarized of all time spent in each respective garden for the week. Since volunteer commitment is small in relation to the total effort (about $2 \%$ of the total), paid and volunteer times were merged in this study.

Data were entered in Excel (Microsoft, Redmond, Wash.) spreadsheets and analyzed using the SAS statistical package for repeated measures (Littell et al., 1996). Weekly effort means were separated using least-squares significant difference techniques (Littell et al., 1996). For garden comparisons, data were clustered by annual total and week-by-area efforts using the SAS statistical package. Annual total effort per garden was calculated and gardens of similar effort patterns were clustered using the average linkage method. In average linkage, the distance between two clusters is the average distance between pairs of observations, one in each cluster (Littell et al., 1996). Effort by unit area per week per garden was grouped using the density clustering method with the $k$ th-nearest-neighbor option (Littell et al., 1996). Density clustering was followed by density linkage, which is a class of clustering methods using nonparametric probability density estimation to group measurements by similarity (Littell et al., 1996).

\section{Results and discussion}

The 24 gardens evaluated for plant maintenance effort were grouped into five clusters (Figs. 1-5). Cluster 1 consists of 

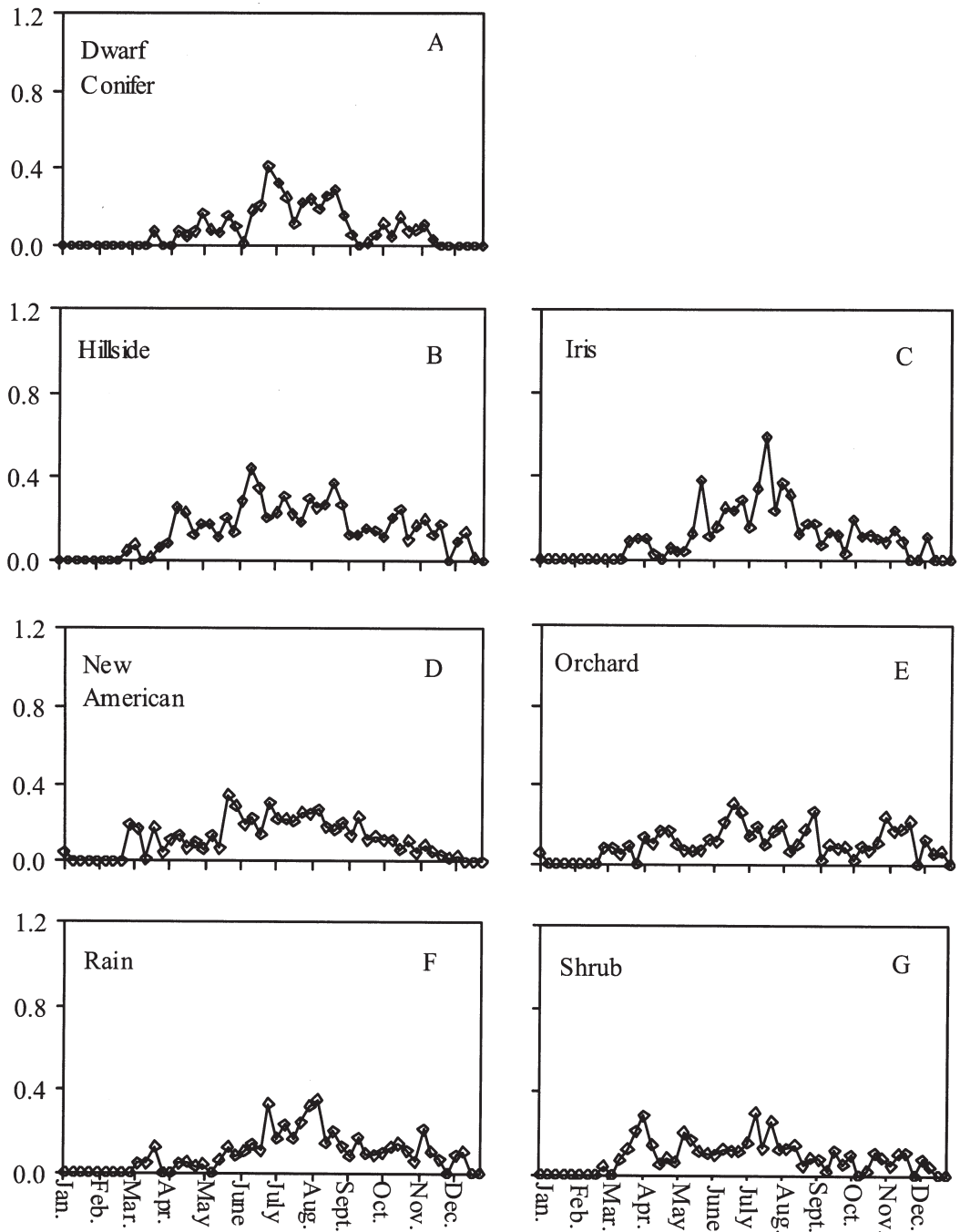

Weeks within month
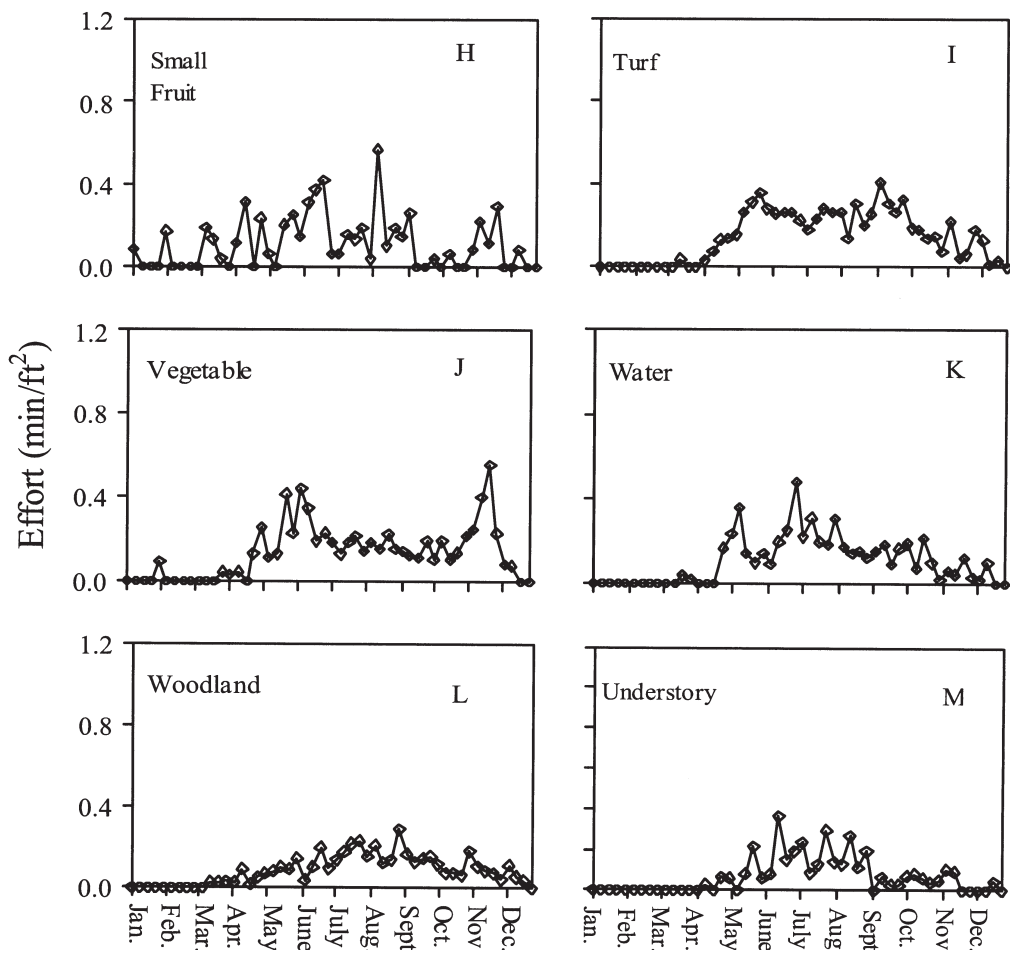

Weeks within month container gardens only (Fig. 1). Effort for Cluster 1 began in March and from April to mid-June sharply increased to peak at $12.0 \mathrm{~min} / \mathrm{ft}^{2}\left(129.17 \mathrm{~min} \cdot \mathrm{m}^{-2}\right)$ per week, decreased steadily to about one-half peak effort by mid-September, increased slightly in October and November, and decreased sharply by December (Figs. 1 and 6A). Peak effort for containers exceeded all other gardens' peak efforts by 10 to 40 times (Figs. 1-5). Average total annual effort devoted to container gardens was 69.4 $\mathrm{min} / \mathrm{ft}^{2}\left(747.04 \mathrm{~min} \cdot \mathrm{m}^{-2}\right)$ per week, 5 to 20 times higher than other gardens evaluated (Fig. 7).

Plants grown in containers are exposed to environmental challenges unlike plants in ground beds. The medium in a container is elevated and becomes warmer than soil, drains and dries quickly, and requires frequent application of water and fertilizer. Plants are elevated, often unprotected, and easily damaged and broken by wind. More and varied plant materials are grown in containers per unit area than in ground beds (Tables 1 and 2). A goal for growing plants in containers is to achieve a manicured and robust display in vertical and horizontal space. Their high visibility means they need to be especially well maintained, which requires more labor. Additionally, there is media preparation, seasonal plant installation and removal, container storage, etc. The magnitude of biomass, density of planting, array of plant materials, environmental requirements, and aesthetic challenges associated with container gardening create the high effort demand.

Cluster 2 consists of corner, sunny annual, and Victorian gardens (Fig. 2). Effort for these gardens was low and irregular from March to May and November to December with major peaks in June at 0.7 to $1.1 \mathrm{~min} / \mathrm{ft}^{2}(7.53$ to $11.84 \mathrm{~min} \cdot \mathrm{m}^{-2}$ ) per week and October at 0.7 to $1.2 \mathrm{~min} / \mathrm{ft}^{2}$ (7.53 to 12.92 $\mathrm{min} \cdot \mathrm{m}^{-2}$ ) per week, and with about $35 \%$

Fig. 4 (left). Average weekly effort at Allen Centennial Gardens, University of Wisconsin, Madison, for plant maintenance by month over 5 years for gardens grouped into Cluster 4 by cluster analysis. Gardens of Cluster 4 include: dwarf conifer (A), hillside (B), iris (C), new American (D), orchard $(E)$, rain $(F)$, shrub $(G)$, small fruit $(\mathrm{H})$, turf $(\mathrm{I})$, vegetable $(\mathrm{J})$, water $(\mathrm{K})$, woodland $(\mathrm{L})$, and understory (M). $1 \mathrm{~min} / \mathrm{ft}^{2}=10.8 \mathrm{~min} \cdot \mathrm{m}^{-2}$. 

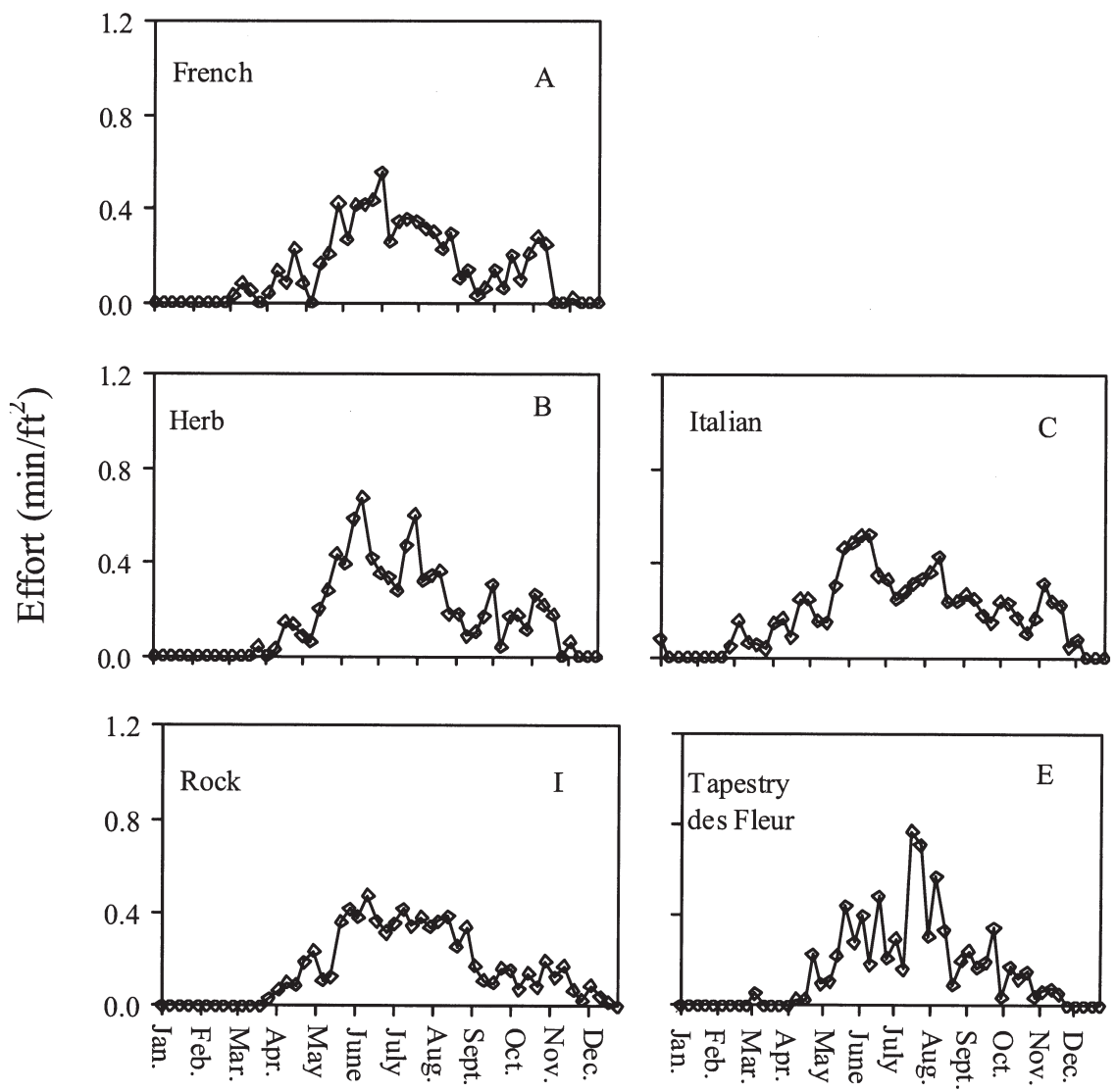

Weeks within month
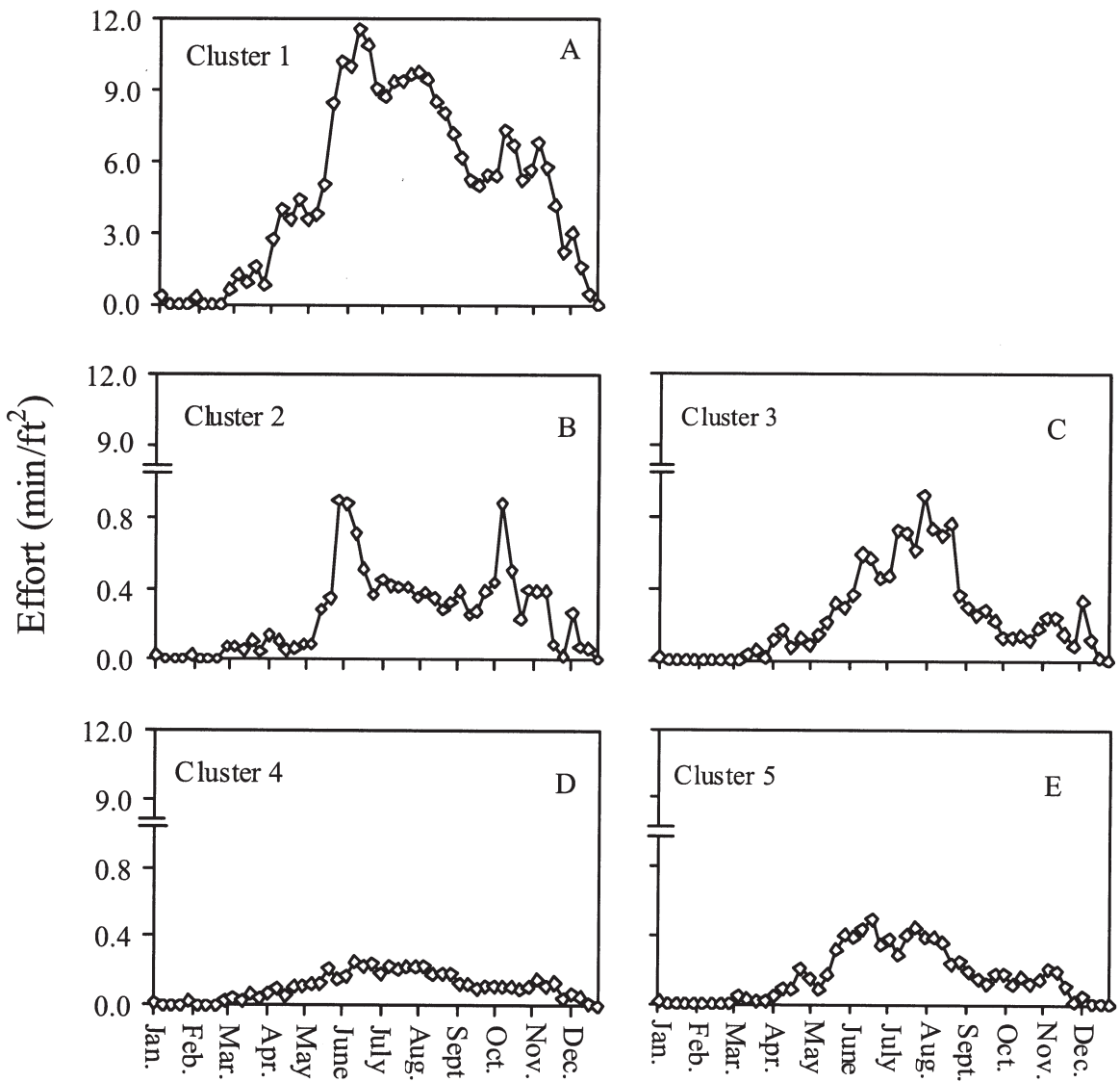

Weeks within month
Fig. 5 (left). Average weekly effort at Allen Centennial Gardens, University of Wisconsin, Madison, for plant maintenance by month over 5 years for gardens grouped into Cluster 5 by cluster analysis. Gardens of Cluster $\mathbf{5}$ include: French (A), herb (B), Italian (C), rock (D), and tapestry des fleur (E). $1 \mathrm{~min} / \mathrm{ft}^{2}=10.8 \mathrm{~min} \cdot \mathrm{m}^{-2}$.

less effort at 0.4 to $0.8 \mathrm{~min} / \mathrm{ft}^{2}(4.31$ to $8.61 \mathrm{~min} \cdot \mathrm{m}^{-2}$ ) per week between June and September (Figs. 2 and 6B). Overall, average total annual effort for sunny annual, corner, and Victorian gardens was 14.1, 13.0, and 12.6 $\mathrm{min} / \mathrm{ft}^{2}(151.78,139.94$, and 135.63 $\mathrm{min} \cdot \mathrm{m}^{-2}$ ) per year, respectively (Fig. 7). This is one-fifth the time required by container gardens (Fig. 1) but four times more than other gardens (Figs. 2-6) evaluated. Plants in gardens of Cluster 2 are annuals grown in ground beds installed in late spring and removed in fall. Spring flowering bulbs are planted in fall after summer plant removal and removed in spring prior to planting for summer, thus the biphasic nature of peaks of June and October. Reduced effort between peaks is likely attributable to the gardens consisting of mostly bedding plants that are disease resistant, compact, durable, and have dehiscent flowers, which require less effort for maintenance. However, our results signify that gardens planted with annuals rank high in plant maintenance effort, especially in spring and fall.

The daylily and English gardens formed Cluster 3 (Fig. 3 ) and consist of long-term plantings of herbaceous and woody perennials. Effort in these gardens occurred between March and December. Effort increased from April through August with peak activity occurring in early August at 0.9 to 1.0 $\mathrm{min} / \mathrm{ft}^{2}\left(9.69\right.$ to $\left.10.76 \mathrm{~min} \cdot \mathrm{m}^{-2}\right)$ per week (Figs. 3 and 6C). Effort around

Fig. 6. Average weekly effort at Allen Centennial Gardens, University of Wisconsin, Madison, for plant maintenance by month over 5 years for gardens within a cluster. Clusters consist of the following gardens: Cluster 1 (A) container gardens; Cluster 2 (B) corner, sunny annual, and Victorian; Cluster 3 (C) daylily and English; Cluster 4 (D) dwarf conifer, hillside, iris, new American, orchard, rain, shrub, small fruit, turf, vegetable, water, woodland, and understory; and Cluster 5 (E) French, herb, Italian, rock, and tapestry des fleur. $1 \mathrm{~min} / \mathrm{ft}^{2}$ $=10.8 \mathrm{~min} \cdot \mathrm{m}^{-2}$. 


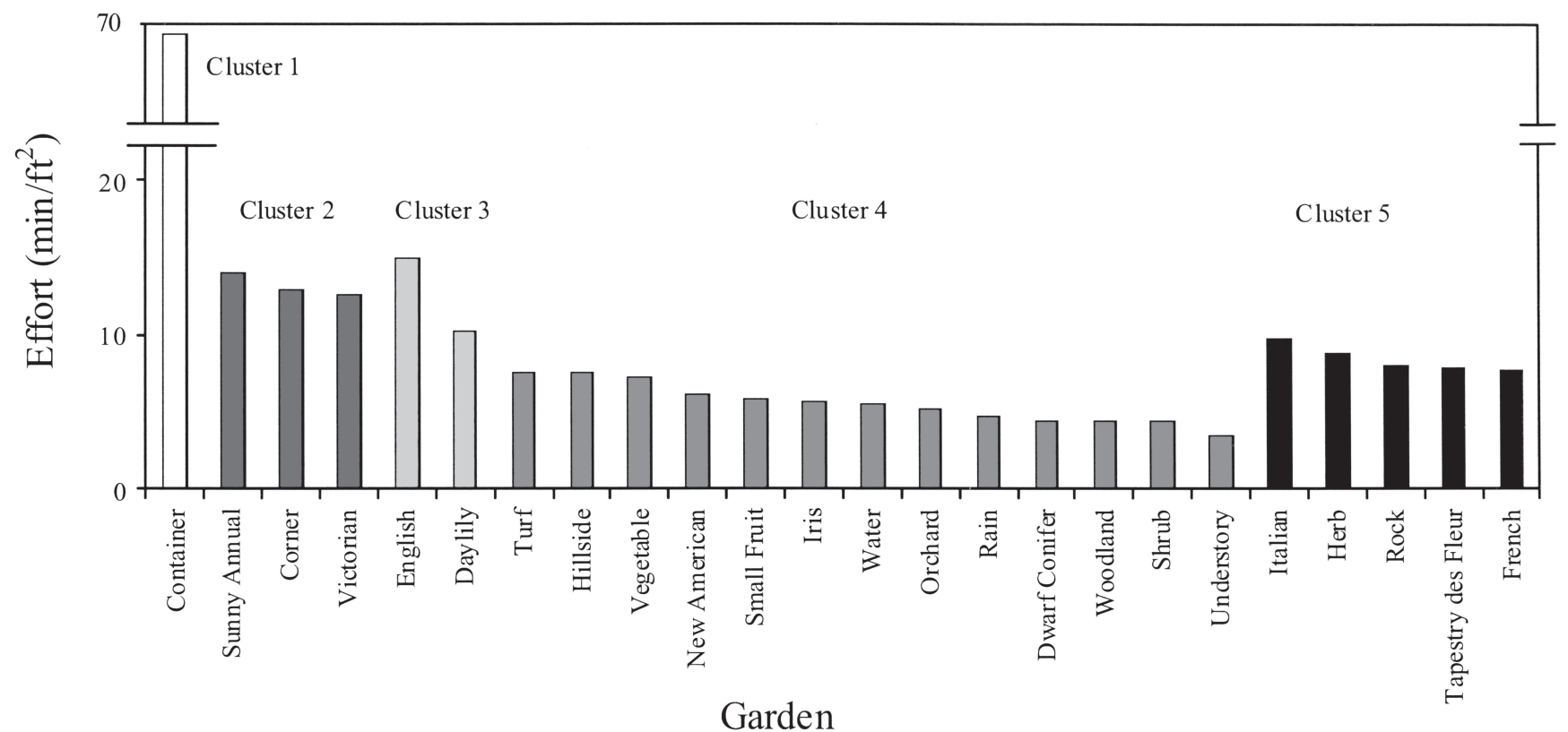

Fig. 7. Average of total annual effort at Allen Centennial Gardens, University of Wisconsin, Madison, for plant maintenance by garden for 24 gardens over 5 years. Gardens of like shading grouped into respective clusters by cluster analysis. 1 min/ $\mathrm{ft}^{2}=10.8 \mathrm{~min} \cdot \mathrm{m}^{-2}$.

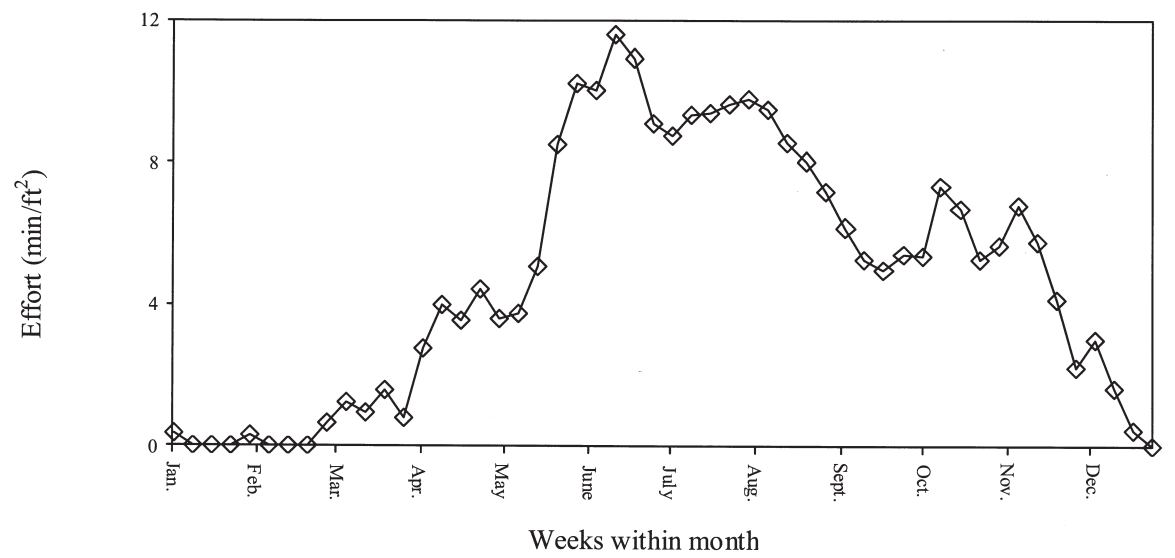

Fig. 8. Average weekly effort for plant maintenance at Allen Centennial Gardens, University of Wisconsin, Madison, over 24 gardens over 5 -years. 1 min $/ \mathrm{ft}^{2}=$ $10.8 \mathrm{~min} \cdot \mathrm{m}^{-2}$. Least significant difference $=0.75 \mathrm{~min} \cdot \mathrm{m}^{-2}$.

the peak is skewed being a 4 -month duration from April through July and a 2month duration from August through September (Fig. 6C). November and December have small inconsistent effort peaks at 0.2 to $0.4 \mathrm{~min} / \mathrm{ft}^{2}(2.15$ to $4.31 \mathrm{~min} \cdot \mathrm{m}^{-2}$ ) per week. Overall, average total annual effort for English and daylily gardens was 15.0 and 10.3 $\mathrm{min} / \mathrm{ft}^{2}\left(161.46\right.$ and $\left.110.87 \mathrm{~min} \cdot \mathrm{m}^{-2}\right)$ per year, respectively (Fig. 7). In these gardens, plants are selected for longevity and to extend flowering season over several months with a climax of floral display midsummer. This imposed nature generates an ebb and flow of effort. The 4-month duration of effort early season reflects a period during active plant growth preparing plants for optimum aesthetic floral display in July and August. Reduction in effort over a 2-month period coincides with reduced end-of-season plant growth and the wane of flowering (Figs. 3 and $6 \mathrm{C}$ ). Removal of plant residue and late season garden clean-up account for effort peaks of November and December.

The dwarf conifer, hillside, iris, new American, orchard, rain, shrub, small fruit, turf, vegetable, water, woodland, and understory gardens form Cluster 4 (Fig. 4). This is about $50 \%$ of the gardens evaluated in this study and they comprise the cluster of gardens with least effort. Effort patterns consisted of a series of minor amorphous peaks from March through December ranging from 0 to $0.6 \mathrm{~min} / \mathrm{ft}^{2}\left(6.46 \mathrm{~min} \cdot \mathrm{m}^{-2}\right)$ per week (Fig. 4). Effort formed a crest from June through August when averaged over gardens of this cluster (Fig. $6 \mathrm{D}$ ). Average total annual effort per garden in this cluster ranged from 3.5 to 7.7 $\mathrm{min} / \mathrm{ft}^{2}\left(37.67\right.$ to $\left.82.88 \mathrm{~min} \cdot \mathrm{m}^{-2}\right)$ per year (Fig. 7). Several explanations can account for low effort of these gardens. The dwarf conifer, hillside, orchard, shrub, small fruit, and woodland gardens are planted mostly with woody ornamental trees and shrubs, which require fewer repetitive annual maintenance tasks by nature and thus need less effort. The array of plants in each garden is low being monoculture for the turf garden and only 28 taxa in each of the vegetable and new American gardens. Accordingly, effort is less diverse and concentrated within time. The new American garden implements durable plants spaced closer reducing plant maintenance (Oehme and van Sweden, 1998; Ottersen, 1987). Many plants of the woodland garden are spring ephemerals and dieback after flowering and require little effort.

Cluster 5 consists of French, herb, Italian, rock, and tapestry des fleur gardens (Fig. 5). Effort started in March and ended in November and is characterized by a series of irregular peaks with a tendency for effort to 
peak June through August at 0.5 to $0.8 \mathrm{~min} / \mathrm{ft}^{2}$ (5.38 to $8.61 \mathrm{~min} \cdot \mathrm{m}^{-2}$ ) per week. The average effort pattern for gardens in this cluster is similar to Cluster 4 but of greater magnitude in midseason (Fig. 6E). Average total annual effort for these gardens ranged from 7.7 to $9.7 \mathrm{~min} / \mathrm{ft}^{2}$ (82.88 to $104.41 \mathrm{~min} \cdot \mathrm{m}^{-2}$ ) peryear (Fig. 7 ). Most gardens of Cluster 5 (Fig. 5 A, B, C, and $\mathrm{E}$ ) are formal gardens consisting of few types of herbaceous and woody perennials. The low array of plants and their perennial nature result in the reduced effort. However, the formal style of gardens in this cluster requires additional pruning and shaping; thus slightly more effort is required than for gardens of Cluster 4 . The rock garden contains about 800 taxa of plants yet has low effort (Fig. 5D). This can be explained by rocks and boulders occupying about $60 \%$ of garden area, thereby lowering actual plant growing area and creating an illusion of low effort in maintenance for rock gardens. Additionally, plants of the rock garden are small, slow growing, and flower in spring in 2 to 3 weeks; factors associated with less effort.

Weekly average effort for the 24 gardens evaluated over 5 years in this study formed a skewed bell-shaped curve (Fig. 8). Effort started in March, increased sharply over 2 months from April to June, peaked in June, and decreased over 6 months from June to December with several lesser peaks. Peak effort in June was $11.6 \mathrm{~min} / \mathrm{ft}^{2}$ (124.87 $\mathrm{min} \cdot \mathrm{m}^{-2}$ ) per week with lesser peaks of effort in August, October, and November of $9.8,7.3$, and $6.7 \mathrm{~min} / \mathrm{ft}^{2}$ $\left(105.49,78.58\right.$, and $\left.72.12 \mathrm{~min} \cdot \mathrm{m}^{-2}\right)$ per week, respectively. The sharp rise of effort from April to June coincides with transition into the growing season and outset of plant growth. The primary tasks at this time consist of winter clean-up, hoeing, mulching, staking, and plant installation. The peak in August coincides with full flower and dead-heading, pruning, and staking. Peaks in October and November mark end-of-season dismantling of gardens, fall bulb installation, and preparation for winter.

Effort tracking of the 24 gardens over 5 years; a mostly different labor pool each year; gardens changing with age; seasonal and annual weather variations; and the wide assortment of annual to perennial herbaceous and woody plants grown form a sound base from which to ascertain the effort required to maintain various types of landscapes at this latitude. Regardless of garden composition, this data can be used to gauge effort and predict cost.

This study clearly shows differences in effort for plant maintenance exist among gardens of various plant composition. Gardens were grouped into clusters based on their patterns of effort. The magnitudes and timing of effort among gardens vary widely and demonstrate the importance of this information for use in planning and managing public and private gardens. The current approach to garden maintenance being classified as low or high maintenance ((Behme, 1969; Oehme and van Sweden, 1998; Ottersen, 1987), or to specific plant culture (Angley et al., 2002; Colton, 1981; Dietrich, 1994; DiSabato-Aust, 1998; Fee, 2002) represents abstractly the real commitment required for plant maintenance collectively for all plants of a garden. Enumeration of plant maintenance is possible and should be used to predict the cost of garden management.

Patterns of effort found in this study can assist in making choices of garden composition, plant type, and combinations of plants or gardens to meet maintenance expectations of time and budgets. Gardens of containers or annual plants require the most resources and would be suitable when time or financial resources exist to meet this level of effort. Similarly, a garden requiring low effort would be suited to a management budget with limited resources. Effort patterns found in timing and magnitude allow for creating garden composition combinations to meet the goals of the owner. Composition of gardens can be selected and built on an area basis to achieve goals concerning effort. Gardens that require high maintenance can be planted for owners with a limited budget if they are planted in small areas.

Student availability at ACG is opposite of the academic calendar beginning in mid-May and ending early-September. Thus, peak student effort impact at ACG is from mid-May to early-September during summer break. This pattern might be assumed to skew and reduce effort in spring and fall forming false representation of true need. However, tasks requiring effort prior to mid-May and after early September are completed to expectations at ACG. Additionally, frost-free date in spring and killing frost in fall define the focus of effort and align closely with the academic timetable and availability of student labor. Thus, if bias exists with the onset or end of effort for plant maintenance throughout the year, it is minimal.

The magnitude of effort found in this study for all gardens may be upwardly inflated as a result of our labor force being students and less skilled than professional gardeners. A requirement for hire at ACG is contingent upon garden maintenance experience. If bias exists upwardly in our data due to level of experience, it is slight and evenly distributed across all gardens. Additionally, the duration of this study over 5 years, with hired labor different each year, should minimize upward bias of effort.

Future analysis of effort for plant maintenance should challenge data presented in this study by including evaluation of gardens with similar plant composition while varying garden size, location, and personnel. Any economy of garden scale in relation to effort, needs to be investigated since gardens evaluated in this study were fairly small. Additionally, comparison is needed in effort for plant maintenance between temperate and tropical regions.

\section{Literature cited}

Angley, S., E. Horsey, and D. Roberts. 2002. Landscape estimating and contract administration. Delmar Learning, Clifton Park, N.Y.

Behme, R.L. 1969. Bonsai, saikei and boneki. Morrow, New York.

Colton, S. 1981. Landscape cost estimating. Environmental Ind., Calabasas, Calif.

Dietrich, N.L. 1994. Kerr's cost data for landscape construction. Van Nostrand Reinhold, New York.

DiSabato-Aust, T. 1998. The well-tended perennial garden. Timber Press, Portland, Ore.

DiSabato-Aust, T. 2003. The well designed mixed garden. Timber Press, Portland, Ore.

Fee, S.H. 2002. Landscape estimating methods. R.S. Means Co., Kingston, Mass.

Littell, R.C., G.A. Milliken, W.W. Stroup, and R.D. Wolfinger. 1996. SAS system for mixed models. SAS Inst., Cary, N.C.

Ode, A.H. 1987. The essence of good maintenance. The Public Garden, Swarthmore, Pa.

Oehme, W. and J. Van Sweden. 1998. Bold romantic gardens. Spacemaker Press, Washington, D.C.

Ottersen, C. 1987. The new American garden. Macmillan, New York. 